\title{
The Role of Self-Efficacy in the Relationship Involving Challenge and Hindrance Stressors and Job Satisfaction
}

\author{
Okechukwu E. Amah* \\ Chevron Nigeria Limited, 2 Cheuron Drive Lekki Penninsula, Lagos Nigeria.
}

*Corresponding Author: E-mail: amahoe@chevron.com

\begin{abstract}
This paper examines the validation of the two-dimensional work stressors, challenge and hindrance stressors, and their interaction with self-efficacy to predict job satisfaction. Survey among 393 employees of some companies in Nigeria, showed some similarities and differences from results obtained in other settings. Specifically, the research validates the two-factor structure for challenge and hindrance stressors, and also established that self-efficacy interacted with challenge stressor to predict job satisfaction. However, the differential effects of the stressors on job satisfaction established by past research in other settings were not confirmed. This result obtained in this research supports other studies that obtained different results when stress models developed in other settings were tested in Nigeria. Consequently, the research recommends that the differential effects of challenge and hindrance stressors on job satisfaction established by past research require further validation to determine generalisation. Also selfefficacy did not interact with hindrance stressor to predict job satisfaction as hypothesised. This implies that employers must find another way to help individuals manage the effect of hindrance stressors. Generally, the research indicates that self-efficacy is an important variable in the understanding of employee behaviour in work stressors characterised as challenge and hindrance stressors.
\end{abstract}

Keywords: Challenge stressor, Hindrance stressor, Job satisfaction, Self-efficacy.

\section{Introduction}

Work stress has negative effects on the health and behaviour of employees; hence, organizations spend huge resources in its management [1] Situations that lead to stress in the work environment is ubiquitous, and cannot be obliterated, hence, employees will have to manage them in order to be effective. Consequently, studies have been carried out aimed at documenting the effects of stress on organizational outcome and individual behaviour $[2,3,4]$, so as to enhance the effectiveness of stress management policies in an organisation. However, results obtained have not been consistent; a situation that is attributed to possible differential effects of stressors on individuals (see $[2,3]$. To account for the conflicting results obtained by past studies, [2] developed a two-dimensional framework of work stressor. The dimensions are labeled as hindrance stressor and challenging stressor. According to [5] challenge stressor is appraised 'as potentially promoting personal growth and achievement', while hindrance stressor is 'appraised as potentially constraining personal development and work accomplishments'. [2] established the uniqueness of the two dimensions, and their differential effects on job satisfaction. Other studies have found similar effects on other work outcomes $[3,5]$, extended the research to include the interactive effect of organisational support [4]. The study by $[2,5]$ are particularly useful in the current study, in that all the studies involve the relationship among the two dimensions of stressors and job satisfaction. However, there are two major differences between the current study and the two studies above. Firstly, the current study did not assume that individuals are passive in stress models, and thus, tested the interactive role of an individual difference variable, selfefficacy, in the stressor/ work outcome model. [2] had identified the inclusion of personality trait as a possible area of extension of their study. According to [3], stress is defined as '... an individual's psychological response to a situation in which there is something at stake for the individual, and where the situation taxes or exceeds the individual's capacity or resources'. From this definition, individual appraisal and perception are very necessary in determining what is stressful, and how individuals react to work situations. Thus, the same situation can be perceived differently by two individuals based on their individual differences. Consequently, in establishing the relationships involving work 
stressors and work outcomes, the role of individual differences must be accounted for. As discovered by past studies, individual differences affected the self report of the various forms of stress [6, 7]. These findings should be taken further to establish if individual differences will still play interactive role in a stress model containing the two-dimensional framework of work stressors.

Secondly, the participants in the studies by $[2,5]$ were taken from USA setting, while the current study participants came from a Nigeria setting. [2] had mentioned that generalisation of their results should be pursued by future studies. Furthermore, [8, 9] while attempting to replicate stress models developed in USA found differential effects of stressors in the participants from Nigeria and Ghana respectively. It is therefore, an important area of inquiry to find out if the results obtained in the research by $[2,5]$ can be generalised with sample from Nigerian.

There are two main aims of the current study. The first is to validate the two-dimensional stress framework by confirming the factorial structure of the two categories of self-reported work stressors identified by [2]. The second aim is to test the interactive roles of self-efficacy in the relationship involving the two categories of stress and work attitude. The choice of job satisfaction is not accidental. Job satisfaction affects organisational commitment [5] and turnover [10]. These variables have far reaching influence on the success of organisations. Consequently, understanding how individual difference will affect the relationship between work stressors and job satisfaction is an important step in enhancing organisational effectiveness.

\section{Review of Literature and Hypotheses}

Challenge and hindrance stressors have been found to have differential effects on job attitudes. For example, [5] found that challenge stressor had positive effect on job satisfaction, while hindrance stressor had negative effect on job satisfaction. Social exchange theory can explain this differential effect. When the work environment is perceived as promoting personal growth and development, the individual who benefits from this work environment, will reciprocate by positive attitude to the job, hence, the positive relationship between challenge stressor and job satisfaction. Conversely, a work environment perceived as constraining personal development and work accomplishment will elicit negative emotional reaction to the job, hence, the negative relationship between hindrance stressor and job satisfaction. Similarly, the balance theory [11], postulates that individuals choose balance state or maintain congruency in their behaviour in social setting. For example, when an individual perceives his/her work environment as constraining development and work accomplishment, the individual will not have positive emotional disposition to the job so as to maintain a balance state [2, 12]. Based on these the following hypotheses are tested:

Hypothesis 1: Challenge stressors will be positively associated with job satisfaction

Hypothesis 2: Hindrance stressor will be negatively associated with job satisfaction

Self-evaluation has become an important variable in understanding behaviours in the workplace [13]. According to [14], 'Self-influences affect the selection and construction of environments. The impact of most environment influences on human motivation, affect, and action, is heavily mediated through self-process' Thus, making the assumption that employees will always be passive in a potentially stressful situation comes with a price, since individuals hold explicit beliefs about their performance in such situation, and these beliefs will affect their behaviour. An important self-belief that has been widely studied is selfefficacy [15-17] sees self-efficacy as individual's belief about being able to perform a task. Studies have established significant relationship between self-efficacy and performance [15, 16], and work outcomes [16]. However, the testing of the moderating role of self-efficacy in the relationship involving work stressors and work outcomes produced conflicting results [3,18]. [3,5] stated that the inconsistent findings may arise from the fact that work stressors were not categorized into challenge and hindrance stressors. Thus, it is an appropriate area of inquiry to ascertain if selfefficacy will have consistent interactive role when the work stressors are categorized accordingly. For example, individuals high in self-efficacy, work hard, are persistent, and use problemsolving coping mechanism in task perceived as challenging. Consequently, the meaning such individuals give to challenge stressor, perceived as enhancing personal growth will be positive, and this will modify the relationship between challenge stressor and job satisfaction. This assertion is supported by [19] which states that 'People with high assurance in their capabilities approach difficult tasks as challenges to be mastered rather than as threats to be avoided. Such efficacious outlook fosters intrinsic interest and deep engrossment in activities'. [20] also asserted that environmental stressors interact 
with individual characteristic to produce stress reactions. Based on the literature review the following hypotheses are tested:

Hypothesis 3: Self-efficacy will interact with challenge stress such that the relationship between challenge stressor and job satisfaction is improved for individuals with high self-efficacy and deteriorate for individuals with low selfefficacy.

Hypothesis 4: Self-efficacy will interact with hindrance stress such that the relationship between hindrance stressor and job satisfaction is improved for individuals with high self-efficacy and deteriorate for individuals with low selfefficacy.

\section{Methodology of Research}

\section{Sample and Procedure}

Participants were drawn from four organisations in the financial and oil industry. Ten employees from these organisations who took part in a senior management training facilitated by the author agreed to participate in the survey. They were each given sixty questionnaires to be administered in their respective organisations. The students were instructed to distribute the questionnaires randomly to their fellow employees. A cover note attached to the questionnaires assured participants of the confidentiality of information provided. Each of the students agreed to place a locked box in their organisations for participants to drop off the filled questionnaires. The key to the box was with the author and participants were informed of this arrangement. Four hundred filled questionnaires were collected by the author (response rate was $67 \%)$. After removing the questionnaires with substantial missing data, only 393 questionnaires were used for the analyses. Majority of the participants were female (67\%), and single (56\%). The average age of the participants was 41 years $(\mathrm{SD}=3.2)$, while $70 \%$ of them were either junior or senior employees.

\section{Materials}

Participants responded to the challenge and hindrance stressor items via a Likert scale $(1=\mathrm{No}$ stress to $5=$ very much stress), while other survey items had Likert scale of $1=$ strongly disagree to $7=$ strongly agree.

Job satisfaction was measured using [21] scale. Five items measured the general satisfaction with current job. Example item is 'Generally I am satisfied with my job'. The Cronbach Alpha for the job satisfaction scale is 0.76. Self-efficacy was measured using [22] scale. Sample item include 'I am confident I can deal efficiently with unexpected events'. Cronbach Alpha was 0.85. Challenge and Hindrance stressors were measured using [2] scale. Participants were expected to record on a scale of 1 to 5 the extent to which certain events result in stress in their job. Sample item for the challenge stressor is 'The scope of responsibility my position entails', while that of hindrance is 'The degree to which politics rather than performance affects organisational decisions'. Challenge and hindrance stressors have Cronbach Alpha of 0.86 and 0.71 respectively.

\section{Results}

All the study variables have acceptable Crobach's Alpha of .7 and above. The descriptive statistics, reliabilities and intercorrelations are reported in Table 1. The correlation between challenge stressor and job satisfaction is -.17 , while that between hindrance stressor and job satisfaction is -.23 , and both are significant at $\mathrm{p}<0.01$. The negative correlation between job satisfaction and hindrance stressor fully supports hypothesis 2, while the negative correlation with challenge stressor is opposite to hypothesis 1. Thus, hypothesis 1 is only partially supported. Selfefficacy was not significantly correlated with challenge or hindrance stressors. The correlation between challenge and hindrance stressors is .3. This is an indication that the two variables are distinct since the variance they share is only $9 \%$.

\section{Preliminary Analyses}

The data for all the study variables was obtained through self-report. To establish the level of common method variance, unrotated principal factor analysis was done using data for the four study variables. The first factor extracted only $18.8 \%$ compared to $59 \%$ extracted by the remaining factors. The result is an indication that the level of common method variance is low [23]. Discriminant validity is confirmed since the square of the bivariate correlation between any two factors is less than the variance extracted by each factor [23].

To establish that the distinctness of the two stressor variables, confirmatory factor analyses was carried out using Analyses of Moments of Structures (AMOS). Two models were developed and tested, and various fit criteria were used to identify the model that adequately fit the data on the two stressor factors [24]. The first model allowed the six items that measured the challenge stressor to load on a factor, while the four items 
Table 1: Means, standard deviations, reliabilities and intercorrelations among variables

\begin{tabular}{llllll} 
Variables & $\mathbf{1}$ & $\mathbf{2}$ & $\mathbf{3}$ & $\mathbf{4}$ & $\mathbf{5}$ \\
\hline 1.Job satisfaction & $(0.76)$ & & & & \\
2.Self-efficacy & .08 & $(0.85)$ & & & \\
3. Challenge stressor & -.17 & .08 & $(0.86)$ & & \\
4.Hindrance stressor & -.23 & .01 & .30 & $.0 .71)$ & -.3 \\
5. Sex & -.12 & -.04 & .01 & -.03 & .15 \\
6. Age & -.16 & -.06 & -.03 & -.02 & .6 \\
7. Marital status & -.17 & -.05 & 3.01 & 2.72 & 0.93 \\
Mean & 3.74 & 5.63 & 1.09 & \\
SD & 1.73 & 0.92 & & \\
\hline
\end{tabular}

Notes: $\mathrm{N}=393$. Correlation values with absolute values greater than 0.1 are significant at $\mathrm{p}<0.01$. ( ), Reliabilities.

Table 2: Confirmatory factor analyses model fit indices for challenge and hindrances stressors

\begin{tabular}{|c|c|c|c|c|c|c|}
\hline Model & CFI & GFI & RMSEA & $x^{2}$ & df & $\mathrm{x}^{2 / \mathrm{df}}$ \\
\hline Two-factor model & 0.97 & 0.97 & 0.06 & 74.95 & 31 & 2.42 \\
\hline
\end{tabular}

CFI, Comparative fit index; GFI, Goodness-of-fit index; AGFI, Adjusted goodness-of-fit index; ${ }^{2}$, Chi-square; df, degree of freedom; RMSEA, Root mean square error of approximation; $p$, significance value

that measured the hindrance stressor loaded on another factor. No cross loading from one factor to the other was allowed. The second model allowed all the ten measurement variables to load on only one factor. Initial modification indices showed that better fit can be obtained in the two-factor model if two items in the challenge stressor are allowed to correlate. This modification gave a better fit for the model estimation. The single factor model has a very poor fit to data, and the measurement variables for the hindrance stressor had loadings between 0.2 and 0.35 on the single factor. The indices for each model are shown in Table 2. Clearly the fit indices for the two-factor model are better than those of the single factor model. The fact that a two-factor model is better than a single factor model is an indication that the participants in this study clearly differentiated the challenge and hindrance stressors as two separate factors. Figure 1 showed that the items on each factor have high loading, and accounted for high variance in the factor. The correlation between the two factors is 0.31 .

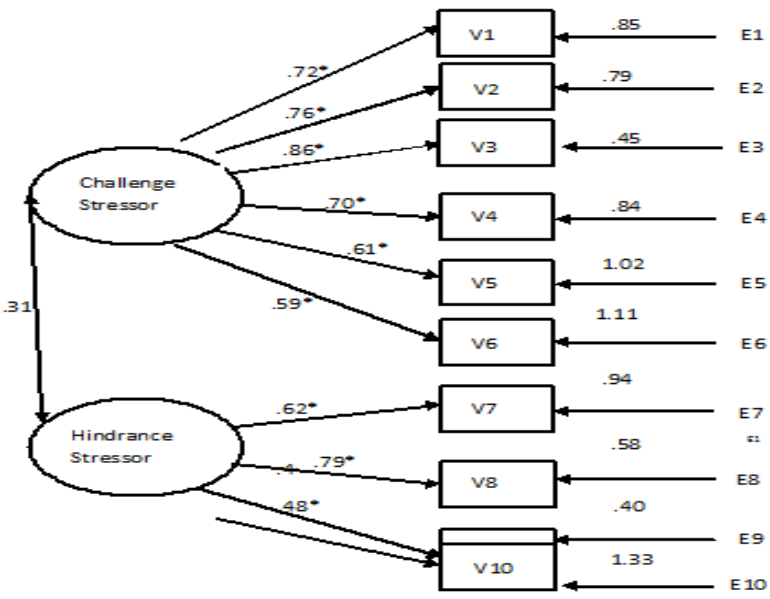

Fig. 1: Stressor scale (Confirmatory factor analysis)

\section{Regression Analyses}

Hypotheses 1 and 2 were tested using hierarchical regression analyses. The control variables, sex, age and marital status were entered in step 1 ; the two stressors were entered in step two. Selfefficacy was entered in step three and the interaction terms involving the stressors and selfefficacy were entered in step 4. To avoid multicollinearity, the variables involved were centered prior to calculating the interaction terms [25]. As indicated in Table 3, after controlling for the demographic variables, the two stressors, challenge stressor (-.11), and hindrance stressor (.20) were negatively and significantly related to job satisfaction. Thus, hypothesis 1 is partially confirmed, while hypothesis 2 is fully confirmed. Self-efficacy had positive significant relation with job satisfaction, and accounted for $3.0 \%$ in the variance of job satisfaction. Only the interaction between challenge stressor and self-efficacy showed positive significant relationship with job satisfaction (.14). Thus, hypothesis 3 was confirmed, while hypothesis 4 was not confirmed. The stressor variables and the significant interaction term accounted for $6.2 \%$ and $7 \%$ of the variance in job satisfaction respectively.

To test the nature of the significant interaction term, the sample was divided into low and high self-efficacy score. The low and high self-efficacy participants have scores of one standard deviation below and above mean self-efficacy score respectively. Thereafter, two regression analyses were developed for the high and low self-efficacy participants [25]. The regression for the low selfefficacy participants showed a negative significant relationship between job satisfaction and challenge stressor $(-.19, \mathrm{p}<.005)$. The relationship between job satisfaction and challenge stressor for high self-efficacy participants was negative (-.09), but not significant. The graphs in Figure 2 show that the effect of challenge stressor on job 
Table 3: Regression analyses of job satisfaction

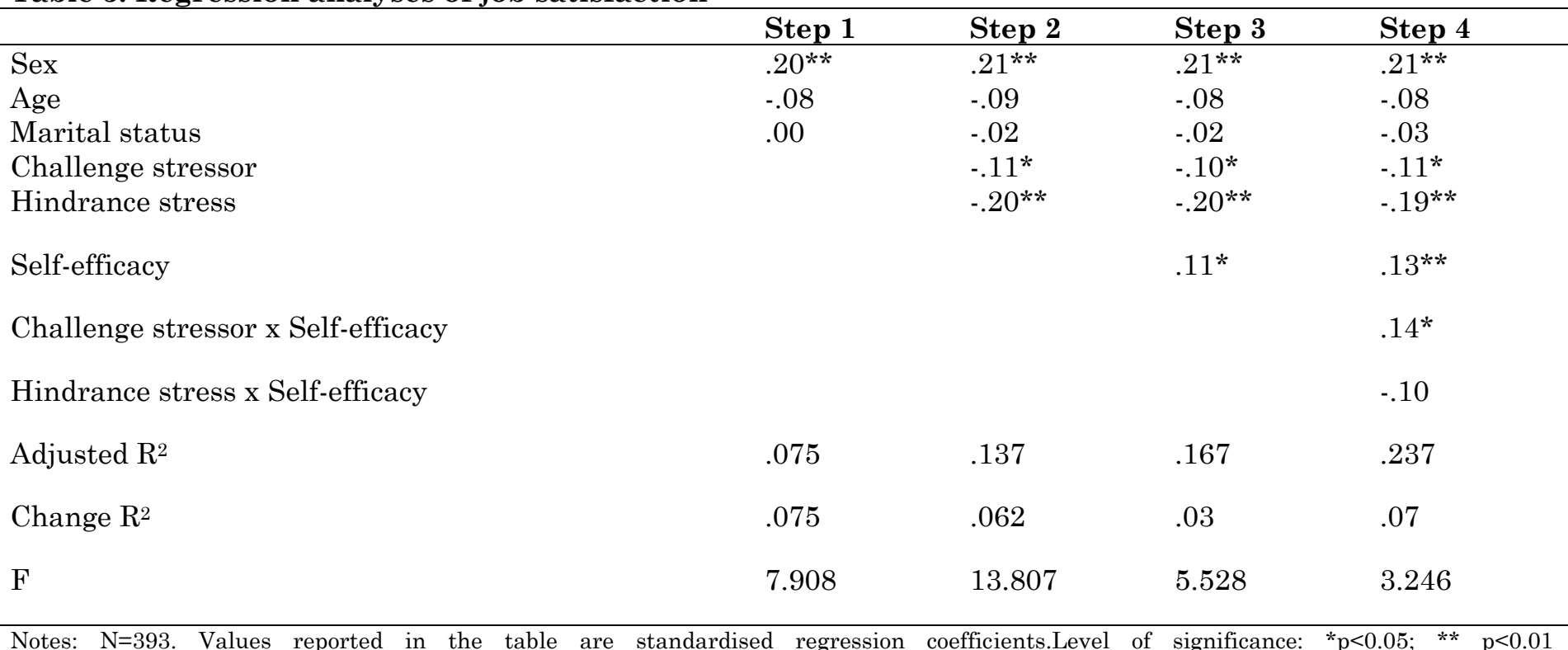

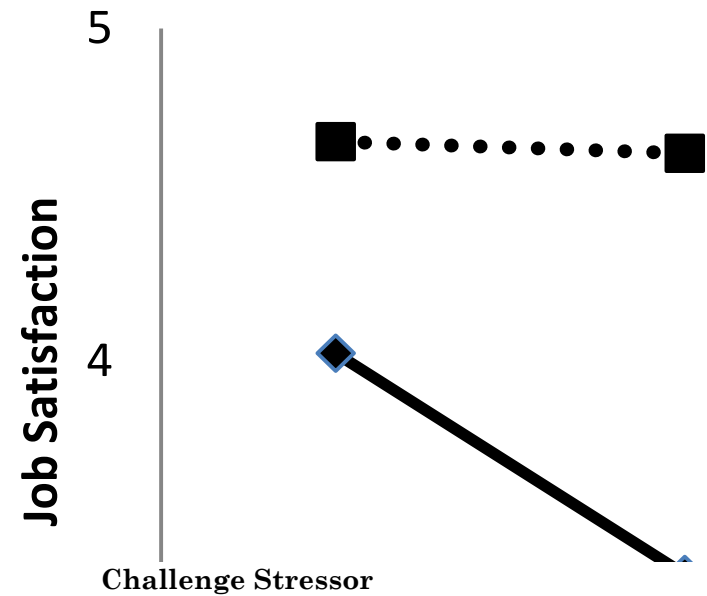

Fig. 2: Self-efficacy interaction prediction of job satisfaction

satisfaction is more for low self-efficacy participants than the high self-efficacy participants.

\section{Discussion}

The fit indices for the two factor stressor model have better fit than the single factor model as indicated in Table 2 . The studies by $[2,3]$ had established the two factor model for challenge and hindrance stressors using samples from USA. The two factor model established in the current study using sample from a different area is an indication that the two factor model for challenge and hindrance stressors has wide application. However, the results of regression analyses do not support the hypothesised differential effects of the two stressors on job satisfaction. Hindrance stressor has negative significant relationship with job satisfaction as hypothesised in hypothesis 2 . The result agreed with those of [2,3]. The relationship between challenge stressor and job satisfaction is negative and significant, which is contrary to the positive relationship established by some previous studies $[2,5]$. This is not the first research to establish that stress models behaved differently when applied to the setting of the current research [8,9]. The non-differential results obtained in the current research may be a wake-up call that it is too premature to generalize the differential effects of the two-dimensional framework of work stressor. Another explanation may be that the current result is unique to the sample used since majority of the participants (60\%) have low self-efficacy score. Positive relationship between challenge stressor and job satisfaction assumes that individuals will perceive challenge stressor as enhancing personal growth, and will therefore value a work environment and job that provide such opportunity. Not all the employees will perceive challenge stressor as a challenge that must be embraced to achieve personal growth [26]. Only individuals with high self-efficacy will embrace highly demanding jobs. This is because performing excellently in such jobs will provide intrinsic value to high self-efficacy individuals, and this in turn enhances their self-worth further. This assertion is corroborated by the fact that past stress studies have determined that stress models behaved differently in the Nigeria context.

The relationship between self-efficacy and job satisfaction was positive and significant. Some studies have established direct positive relationship between self-efficacy and job satisfaction [27, 28]. The argument usually put forward is that high self-efficacy individuals gravitate to jobs that are challenging, and provide means for enhancing personal growth, and that 
successfully performing such tasks provides intrinsic reward that further enhances selfefficacy [29]. High self-efficacy individuals in such job will be positively disposed to the job. However, past research has also established that when the relationship between self-efficacy and job satisfaction is subjected to covariance analyses, the model with only indirect relationship through work and job characteristics had a better fit.

The only significant interaction term in the study is that between self-efficacy and challenge stressor. Further analyses of the result indicated that the regression of challenge stressor and job satisfaction for high self-efficacy individuals produced non-significant result, while that for low self-efficacy individuals was negative and significant. Moderating effects of personality disposition on the work stress and work outcome relationship has been established by past studies [18]. High self-efficacy individuals believe in their ability to carry out assigned tasks, and will apply great effort and persist even in situation of challenging stress [26]. Though this study did not measure coping method used by participants, it is believed that high self-efficacy individuals apply problem-solving coping style, and therefore will persist in challenging situations, while low selfefficacy will give up easily [26]. Self-efficacy did not moderate the relationship between hindrance stressor and job satisfaction. Self-efficacy did not moderate the relationship between role ambiguity, a component of hindrance stressor, and job satisfaction [16]. Hindrance stressor also includes organisational politics, rigid work rules and fear of job security [5]. These are viewed as not supporting personal growth and not accomplishment friendly. It appears that the best way to manage hindrance stress is to minimize occurrence since its effect cannot be hedged by positive self-evaluation.

\section{Theoretical and Practical Implications}

At a general level the research contributes to literature on stress in the following ways. It validated the two-dimensional framework for workplace stressors using participants from environment different from those of the participants used in past studies $[2,5]$. Contrary to the differential effects of the two dimensions of stressor obtained by $[2,5]$ the effects of the two dimensions are both negative. This is not the first time that effects in stress model differ when results from USA are compared to other places [8, 9].The data presented by [30] indicated that people tend to perceive hindrance and challenge stressor as equally stressful. If this is correct, then having same effect on work outcome may not be unusual finding. While reviewing the process of stress appraisal, [30], asserted that the relationship between the stressors and work outcomes is complicated by the presence of 'emotional and cognitive effect associated with appraisal and coping'. These are variables that depend heavily on personality disposition. Thus, it appears that further cross-cultural validation of the differential effects of hindrance and challenge stressor in stress model is needed before a generalized conclusion is drawn.

The study also confirmed possible interactive role of self-efficacy in the two-dimensional stress model. Past studies recognised this role, but never included it in their model. Hindrance stressor is shown in this study to have negative effect on job satisfaction. The interaction of hindrance stressor and self-efficacy did not achieve significance. Thus, individual differences cannot be used to manage the effect of hindrance stressor. Consequently, organisations should make effort to reduce the level of hindrance stressor or eliminate it completely. For example, organisational politics, role ambiguity and red tape are components of hindrance stressor that can be managed by the organisations. Challenge stressor has negative effect on the participants utilized in this research, and self-efficacy moderated this negative effect. Further analysis of the interaction effect indicates that the job satisfaction of employees with high self-efficacy was not affected by the challenge stressor, while the job satisfaction for low self-efficacy was affected. This implies that policies aimed at enhancing selfefficacy will make valuable contribution to employees handling of challenge stressor. Providing mentoring, feedback and supporting environment will create the environment needed for the enhancement of self-efficacy since it is malleable [31, 32]. This does not mean that employers should not be concerned about the level of challenge stressor. Stress generally has physiological effects on individuals [7] and when stress levels are not controlled, the situation will eventually lead to sickness and low productivity. For example, when work load becomes a constant issue in an organisation, employees may become worn out.

\section{Conclusion and Recommendations}

Workplace stressors affect the health and productivity of employees, and ultimately will affect the bottom-line of the organisation. Thus, the understanding of stressors and how they operate will enhance the institution of organisational policies aimed at helping employees manage stress effects. The 
identification of two-dimensional framework for work place stressors is a great advancement in the study of stress in organisation. Equally great is the validation of the framework in other work environments different from the environment where the scale is developed. The effect stressors have on work outcomes is affected by individual differences. The current study advanced the study of stress in two ways. Firstly, it validated the twodimensional stress framework in Nigeria. This validation is necessary bearing in mind the stress models developed have been found to have some differences when applied in the setting of the research. Secondly, the study extended past studies involving two-dimensional stressors by accounting for the effect of an individual difference variable, self-efficacy on the relationship among the dimensions and job satisfaction. The study did not replicate the differential effect challenge and hindrance stressors have on job satisfaction determined by past studies. The study went further to

\section{References}

1. Cooper DV, Dewe PJ, O'Driscoll MP (2001) Organizational Stress: A review and critique oftheory, research, and applications. Thousand Oaks, CA: Sage.

2. Cavanaugh MA, Boswell WR, Roehling MV, Boudreau JW (2000) An empirical examination of self-reported work stress among US managers, J. Applied Psychology, 85:65-74.

3. LePine JA, LePine MA, Jackson CL (2004) Challenge and hindrance stress: relationships withexhaustion, motivation to learn and learning performance, J. Applied Psychology, 89:883-91.

4. Wallace JC, Edwards BD, Arnold T, Frazier DM (2009) Work stressors, role-based performance,and the moderating influence of organizational support, J. Applied Psychology, 94:254-62.

5. Podsakoff NP, LePine JA, LePine MA (2007) Differential challenge stressor-hindrance stressor relationship with job attitudes, turnover intention, turnover, withdrawal behavior: A meta-analysis, J. Applied Psychology.92:438-54.

6. Gallagher DJ (1990) Extraversion, neuroticism and appraisal of stressful academic events. Personality and Individual Differences, 11:1053-57.

7. Huebner ES, Mills LB (1994) Burnout in school psychology: The contribution of personality characteristics and role expectations. Special Services in the Schools, 8:53-67.

8. Akinrele AB, Osamwonyi I, Amah OE (2007) Workfamily conflict model: Application ofAryee's model, African J. for the Psychological Studies of Social Issues, 10:3-16. recommend that this differential effect is far from settled and that future studies should include appraisal and coping style as variables in the model.

All the variables were acquired using self-report. This implies that there will be common method variance. However, the preliminary analyses carried out indicated that the level of common method variance was within the limit allowable for self-report studies. This is not a longitudinal study and hence, causality cannot be inferred from the result. Appraisal and subsequent choice of coping mechanism appears to be major determinants in the sign of the relationship between the dimensions of stress and work out come. Since these variables were not part of the current research, the difference between past research and the current research could not be resolved. Future research should measure these variables so as to understand the relationship between challenge stressor and job satisfaction.

9. Aryee S, Fields D, Luk V (1999) A cross-cultural test of a model of work-family interface, J. Organizational Behaviour, 25:491-511.

10. Griffeth RW, Hom PW, Gaertner S (2000) A metaanalysis of antecedents and correlates of employee turnover: Update, moderator tests, and research implications for the next millennium, J. Management, 26:463-88.

11. Heider F (1958) The psychology of interpersonal relations. New York: Wiley.

12. Boswell WR, Olson-Buchanan JB, Lepine MA (2004) The relationship between work-related stress and work outcomes: The role of feltchallenge and psychological strain, J. Applied Psychology, 64:165-81.

13. Brief AP, Aldag RJ (1981) The self in work organisations: A conceptual review. Academy of Management Review, 6:75-88.

14. Bandura A (1993) Perceived self-efficacy in cognitive development and functioning. Educational Psychology. 28:117-48.

15. Barling J, Beattie R (1983) Self efficacy beliefs and sales performance, J. Organisational Behaviour, 5:41-51.

16. Jex SM, Gudanowski DM (1992) Efficacy beliefs and work stress: An exploratory study, J.Organisational Behaviour, 13:509-17.

17. Bandura A (1977) Self-efficacy: Toward a unifying theory of behavioural change, Psychological Review, 84:191-215.

18. Jex SM, Bliese PD (1999) Efficacy beliefs as a moderator of the effects of work-related stressors: 
A multilevel study, J. Applied Psychology. 84:34961.

19. Bandura A (1994) Self-efficacy. In V.S. Ramachaudran (eds), Encyclopedia of Human Behaviour. 4:71-81. New York: Academy Press.

20. Beehr TA, Newman JE (1978) Job stress, employee health and organisational effectiveness: Afacet analysis, model, and literature review, Personnel Psychology, 31:665-99.

21. Sagie A, Zaidman N, Amichai-Hamburger DT, Schwartz DG (2002) An empirical assessment ofthe loose-tight leadership model: Quantitative and qualitative analysis, J. Organisational Behaviour, 23:303-20.

22. Jerusalem M, Schwarzer R (1992) Self-efficacy as a resource factor in stress process. In $R$. Schwarzer (eds), Self-efficacy: Thought Control of Action. pp.195-213. Washington DC: Hemisphere.

23. Koufteros XA, Vonderembse MA, Doll WJ (2002) Examining the competitive capabilities of manufacturing firms, Structural Equation Modeling: A Multidisciplinary Journal, 9:256-82.

24. Hu LT, Bentler PM (1999) Cutoff criteria for fit indices in covariance structure analysis: Conventional criteria versus new alternatives, Structural Equation Modeling: A Multidisciplinary J. 6:1-55.

25. Aiken LS, West SD (1991) Multiple Regressions: Testing and Interpreting Interactions. CA: Sage.
26. Jex SM, Bliese PD, Buzzell S, Primeau J (2001) The impact of self-efficacy on stress-strain relations: Coping style as an explanatory mechanism, J. Applied Psychology, 86:401-09.

27. Judge TA, Locke EA, Durham CC, Kluger AN (1998) Dispositional effects of job and life satisfaction: The role of core-evaluations, J. Applied Psychology, 83:17-34.

28. Judge TA, Bono JE, Locke EA (2000) Personality and job satisfaction: The mediating role of job characteristics, J. Applied Psychology. 85:237-49.

29. Swann WB, Stein-Seroussi A, Giesler RB (1992) why people self-verify. Personality and Social Psychology. 62:392-401.

30. LePine JA, Podsakoff NP, LePine MA (2005) A meta-analytic test of the challenge stressorhindrance stressor framework: An exploration for inconsistent relationships among stressors and performance, Academy of Management J. 48:76475.

31. Gist M, Mitchell T (1992) Self-efficacy: A theoretical analysis of its determinants and malleability, Academy of Management Review, $17: 183-211$

32. Maurer TJ (2001) Career-relevant learning and development, worker age, and beliefs about selfefficacy for development, J. Management, 27:12340. 